\title{
Representação e Análise de Dados no Quinto Ano do Ensino Fundamental: Proposta de Atividade e Relato de Aplicação*
}

\author{
Yuri Weisshahn ${ }^{1}$, Gustavo Pinho $^{1}$, Simone Cavalheiro ${ }^{1}$, Clause Piana ${ }^{1}$, \\ André Du Bois ${ }^{1}$, Marilton Aguiar ${ }^{1}$, Luciana Foss ${ }^{1}$, Renata Reiser ${ }^{1}$ \\ ${ }^{1}$ Centro de Desenvolvimento Tecnológico - Universidade Federal de Pelotas (UFPel) \\ Caixa Postal 354 - 96.010-610 - Pelotas - RS - Brazil \\ \{yrweisshahn, gcdpinho, simone.costa\}@inf.ufpel.edu.br
}

\begin{abstract}
Computational thinking is a process for problem-solving that includes many skills required for IT professionals and that are also useful for everyday activities of other areas. This paper describes an activity designed for elementary school fifth grade students to develop some of these skills, particularly collection, representation and analysis of data. The Computer unplugged methodology was used, in which computing concepts are introduced to students through games and fun activities. Besides describing the methodology of the activity, this paper also describes the results of applying the activity to three classes of public schools in the city of Pelotas.
\end{abstract}

Resumo. Pensamento Computacional é um processo de solução de problemas que inclui diversas habilidades exigidas de um profissional da área de Computação e que são úteis para atividades cotidianas de inúmeras áreas. Este artigo apresenta uma proposta de atividade para o quinto ano do ensino fundamental que trabalha com algumas destas habilidades, particularmente as de coleta, representação e análise de dados. Como metodologia, foi utilizada a Computação Desplugada, onde são introduzidos conceitos de computação sem o uso do computador, com tarefas lúdicas e divertidas. Além de uma descrição metodológica da atividade proposta, é apresentado o relato e os resultados da aplicação da mesma a três turmas de escolas públicas do município de Pelotas.

\section{Introdução}

A crescente presença e influência de ferramentas computacionais em atividades cotidianas tem alterado o perfil de inúmeras áreas. Diversas escolas, por exemplo, já possibilitam aos alunos o contato com computadores e softwares. No entanto, se limitam a este tratamento [Costa et al. 2012]. Desta forma, defende-se a necessidade de apresentar a Computação, não apenas como um instrumento, mas também como uma forma de solucionar problemas de maneira eficiente [Thinking et al. 2010]. Sob esse panorama, o Pensamento Computacional surge como uma proposta para difusão desta abordagem.

O Pensamento Computacional (PC), do inglês Computational Thinking, pode ser entendido como um conjunto de técnicas que utiliza conceitos da Computação para solucionar problemas. Como proposto em [Wing 2006], a metodologia baseada no PC auxilia a resolução de problemas por meio do uso de conceitos de projeto de sistematização de algoritmos da Ciência da Computação, levando em conta a compreensão do comportamento

${ }^{*}$ Projeto realizado com o apoio do PROEXT - MEC/SESu. 
V Congresso Brasileiro de Informática na Educação (CBIE 2016)

Anais do XXII Workshop de Informática na Escola (WIE 2016)

humano. Também em 2006, Wing apresentou o PC como uma habilidade fundamental para todos, não somente para cientistas da computação.

Dentre as metodologias que podem ser adotadas para o desenvolvimento de habilidades do PC, destaca-se a Computação Desplugada [Bell et al. 2015]. Essa técnica foi desenvolvida com o objetivo de ensinar os conceitos da área da Ciência da Computação sem a necessidade do uso de computadores, o que evidencia o caráter científico dos mesmos. Diversos projetos já disseminam o PC na Educação Básica no Brasil, como por exemplo em [Scaico et al. 2012], [Machado et al. 2010] e [Arantes et al. 2014]. Alguns deles, com objetivos claros de desenvolver habilidades e atitudes consideradas essenciais dentro do PC, outros, indiretamente, introduzem conceitos de Computação.

Este artigo descreve a experiência e os resultados obtidos na realização de uma atividade denominada Cara a Cara, aplicada em três turmas do quinto ano do ensino fundamental de duas escolas municipais de Pelotas. Esta proposta apresenta uma metodologia para desenvolver as habilidades do PC de coleta, análise e representação de dados. $\mathrm{O}$ artigo está organizado como segue. Na Seção 2, se descreve a metodologia utilizada no desenvolvimento do trabalho. $\mathrm{Na}$ Seção 3, se apresenta o relato das aulas, juntamente com seus objetivos e materiais utilizados. A Seção 4 contém os resultados obtidos na aplicação da atividade e uma breve discussão. Na Seção 5, são apresentadas as considerações finais.

\section{Metodologia}

A primeira etapa consistiu na fundamentação teórica do trabalho a partir das características e dimensões do PC. O PC é um processo de resolução de problemas, que inclui (mas não está limitado) as seguintes habilidades [Wing 2006]: formulação de problemas de modo que seja possível usar um computador e outras ferramentas para ajudar a resolvê-los; organização lógica e análise de dados; representação de dados por meio de abstrações, como modelos e simulações; soluções de automação por meio do pensamento algorítmico (como uma série de passos ordenados); identificação, análise e implementação de soluções possíveis com o objetivo de alcançar a combinação mais eficiente e eficaz das medidas e recursos; generalização e transferência desse processo de resolução para problemas variados.

Essas habilidades são reforçadas por uma série de disposições ou atitudes que são dimensões essenciais do PC. Estas disposições ou atitudes incluem: a confiança em lidar com a complexidade; a persistência em trabalhar com problemas difíceis; a tolerância para a ambiguidade; a capacidade de lidar com os problemas em aberto; a capacidade de se comunicar e trabalhar com outros para atingir um objetivo ou solução comum.

A escolha da metodologia de concepção da atividade levou em consideração o perfil do público-alvo e a infraestrutura das escolas públicas do município de Pelotas, que em sua maioria não possui laboratórios de computação com pelo menos uma máquina para cada dois alunos. A atividade foi desenvolvida para alunos de quinto ano de escolas públicas, conforme estabelecido pelo escopo do projeto já aprovado e financiado pelo MEC/SESu. De acordo com esta realidade optou-se por adotar a metodologia da Computação Desplugada [Bell et al. 2015].

A computação Desplugada é uma estratégia que visa ensinar os fundamentos da computação de forma lúdica e sem o uso de computadores. A abordagem pode ser aplicada para pessoas de todas as idades, com diferentes conhecimentos e experiências. Um 
V Congresso Brasileiro de Informática na Educação (CBIE 2016)

Anais do XXII Workshop de Informática na Escola (WIE 2016)

dos objetivos é eliminar as barreiras técnicas e os equívocos sobre o que é realmente a computação. Segundo [Vieira et al. 2013], os princípios da estratégia consistem em não utilizar computadores, ensinar ciência da computação, aprender fazendo, tornar o ensino divertido, não adotar nenhum equipamento especializado, desenvolver variações sobre aplicações das atividades, incluir a comunicação e a solução de problemas para enfatizar a cooperação, desenvolver atividades autossuficientes, ou seja, que possam ser usadas independentemente umas das outras e por fim, ser flexíveis com relação a erros, isto é, pequenos erros não devem impedir que os participantes entendam os fundamentos.

Então, num segundo momento, foram estabelecidas as características do PC a serem abordadas pelo trabalho: coleta, representação e análise de dados. A opção por tais habilidades se deu pela consonância entre as habilidades do PC e os conteúdos referentes ao tratamento de informação previstos para o segundo ciclo (onde se enquadra o quinto ano) dos Parâmetros Curriculares Nacionais [MEC 1997], particularmente, coleta, organização, representação e interpretação de dados. Assim, foi estabelecido que a atividade tinha por objetivo geral desenvolver habilidades básicas de tratamento de informação.

Além disso, de forma a explorar algumas das atitudes essenciais do PC, optou-se por não elaborar uma atividade por meio de aulas puramente expositivas. O desenvolvimento da atividade deveria ser planejado a partir de tarefas lúdicas que promovessem incrementalmente as habilidades e dimensões (tolerância, persistência, comunicação e colaboração) a serem exploradas: na etapa de definição do instrumento de coleta de dados, os alunos deveriam ser instigados a identificar quais características são relevantes para diferenciar pessoas ou objetos; na etapa de coleta, eles deveriam efetivamente realizar o levantamento e a organização dos dados; e na etapa de análise, eles deveriam conseguir extrair informações relevantes destes dados.

A ideia geral desta atividade foi concebida e descrita em [Andrade et al. 2013], cuja inspiração foi o jogo de tabuleiro Cara a Cara [Estrela 1986]. No presente trabalho, além da apresentação detalhada da atividade, propõe-se uma metodologia para o seu desenvolvimento em sala de aula. As etapas da atividade levam à definição e análise de estratégias que conduzam a vitória de um jogo similar ao Cara a Cara. A atividade compreendeu sete encontros, detalhados na próxima Seção.

\section{Descrição da Atividade}

A atividade foi dividida em sete encontros com duração aproximada de $1 \mathrm{~h} 10 \mathrm{~min}$. $\mathrm{O}$ primeiro encontro introduz conceitos estatísticos e o segundo trabalha com a coleta de dados. Do terceiro ao quinto encontro foca-se na organização, representação e análise de dados. Por fim, o sexto encontro prevê a aplicação dos resultados da análise na execução do jogo. O último encontro foi reservado para a avaliação da atividade.

\subsection{Aula 1 - Introdução a conceitos estatísticos: característica, variável e constante}

Objetivos: esta aula buscou introduzir, de maneira lúdica, conceitos básicos necessários para coleta e classificação de dados: característica, valor, constante, variável e frequência. Os conceitos foram trabalhados com o objetivo de promover a reflexão a respeito da relevância de certas características dos objetos em determinados contextos. 
V Congresso Brasileiro de Informática na Educação (CBIE 2016)

Anais do XXII Workshop de Informática na Escola (WIE 2016)

Metodologia: inicialmente, os conceitos básicos foram introduzidos e para cada um dos conceitos foi feita uma breve discussão sobre exemplos presentes na sala de aula. O conceito de característica foi explicado como algo que permite diferenciar ou igualar os objetos; valor foi definido como cada uma das opções assumidas para uma característica; definiu-se constante como a característica cujo valor não varia dentro de um grupo e variável como a característica cujo valor varia; e frequência foi definida como o número de vezes que o valor da característica se repete no grupo. Nesta discussão, também foi enfatizada a importância destes conceitos para a análise e coleta e dados. Após, foi sugerida uma partida do jogo "Quem sou eu?", que teve por objetivo fazer com que os alunos pensassem a respeito das características relevantes na diferenciação de objetos e pessoas. O jogo é constituído de um conjunto de cartas de personagens populares e conhecidos dos alunos. A cada jogador é designada uma carta, que é mostrada a todos os demais jogadores mas não a ele. O objetivo do jogo é descobrir quem é o personagem da sua carta por meio de perguntas com respostas do tipo sim ou não. Para a execução do jogo, foi proposto que os alunos se dividissem em grupos de seis e se sentassem em círculos, para que cada participante visualizasse as cartas dos colegas; cada participante tinha direito a uma pergunta e um palpite em cada rodada. Por fim, foi discutido com os alunos quais características são importantes na diferenciação dos personagens do jogo, relacionando-as com os conceitos de variável e constante.

Materiais: para a execução do jogo foram utilizados cartões retangulares, onde foram impressas imagens de personagens de filmes ou desenhos animados, conhecidos pelas crianças. Foram utilizadas folhas A4 com desenhos de diferentes personagens.

\subsection{Aula 2 - Coleta de dados}

Objetivos: estimular a coleta e organização de dados por parte dos alunos por meio do levantamento de dados de personagens do jogo Cara a Cara. Também fazer com que os alunos levantassem características relevantes na diferenciação desses personagens.

Metodologia: a atividade iniciou-se com a retomada da discussão da tarefa anterior a respeito das características que são importantes na diferenciação de objetos e pessoas. A partir da discussão, foi mostrado para os alunos um cartaz que continha os personagens do jogo Cara a Cara (parte do cartaz está ilustrado na Figura 1).

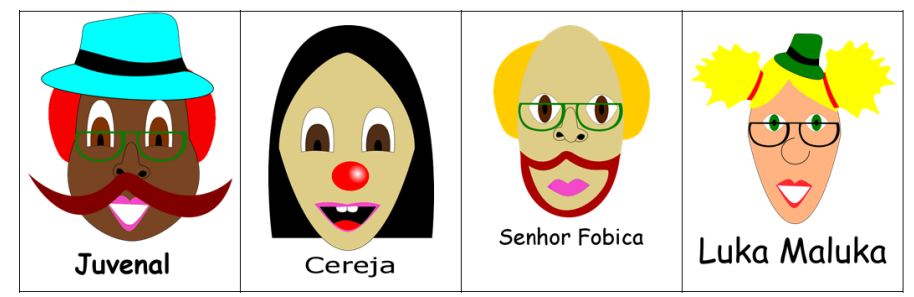

Figura 1. Alguns personagens do Jogo Cara a Cara expostos no Cartaz

A turma então foi dividida em grupos e cada grupo precisava levantar cinco características dos personagens. Para cada característica levantada, deveriam indicar se a mesma era constante ou variável. Após, o professor fez uma breve discussão ressaltando quais características diferenciam os personagens e quais não os diferenciam ou não possuem valores bem definidos. Por fim, foi distribuída uma ficha de coleta com os nomes de todos os personagens. Nesta ficha, foram selecionadas e preenchidas características 
V Congresso Brasileiro de Informática na Educação (CBIE 2016)

Anais do XXII Workshop de Informática na Escola (WIE 2016)

indicadas pelos alunos e foi feita a coleta de dados. Parte da ficha de coleta para os dados dos personagens exibidos na Figura 1 é detalhada na Tabela 1.

Tabela 1. Parte da Ficha de Coleta já preenchida utilizada em aula

\begin{tabular}{l|l|l|l|l}
\hline $\mathbf{N}^{\mathbf{0}}$ & Nome & Cor do Cabelo & Cor dos Olhos & Gênero \\
\hline $\mathbf{1}$ & Juvenal & Vermelho & Castanhos & Masculino \\
\hline $\mathbf{2}$ & Cereja & Preto & Castanhos & Feminino \\
\hline $\mathbf{3}$ & Senhor Fobica & Amarelo & Castanhos & Masculino \\
\hline $\mathbf{4}$ & Luka Maluka & Amarelo & Verdes & Feminino \\
\hline
\end{tabular}

Materiais: foi utilizado um pôster $A 0$, onde estavam impressos os 28 personagens do jogo (parte ilustrada na Figura 1) e fichas de coleta (parte descrita na Tabela 1), uma por aluno, impressas em folha $A 4$. As fichas de coleta continham na primeira coluna os nomes de todos os personagens do jogo e na primeira linha foram preenchidas as características a serem consideradas. As demais células estavam em branco e foram preenchidas pelos alunos.

\subsection{Aula 3 - Representação de dados por tabelas simples e análise dos dados}

Objetivos: promover a necessidade de se organizar os dados coletados, ensinar métodos simples para a representação e análise dos dados.

Metodologia: a partir dos dados coletados na aula anterior na ficha de coleta, foi feita uma série de questionamentos a respeito dos dados coletados com o objetivo de demonstrar a necessidade de organização dos dados. Foi perguntado aos alunos quantos personagens do jogo eram do sexo masculino, se haviam mais personagens do sexo masculino do que do feminino, entre outras. Houve divergência entre as respostas (devido a falha na contagem) e então, essa divergência entre as respostas foi utilizada para motivar a necessidade de representar os dados de forma mais organizada.

Discutiu-se com os alunos que existem diversas formas de representar os dados (tabelas, gráficos, diagramas, etc.) e que a organização dos dados por uma delas pode facilitar e tornar mais rápida qualquer consulta. A partir de então, apresentou-se os elementos e os objetivos de uma tabela de frequência simples (a qual relaciona os valores de uma característica com sua frequência) e se construiu um exemplo desta tabela. Em seguida, os alunos completaram uma folha de exercícios (parte ilustrado na Figura 2).

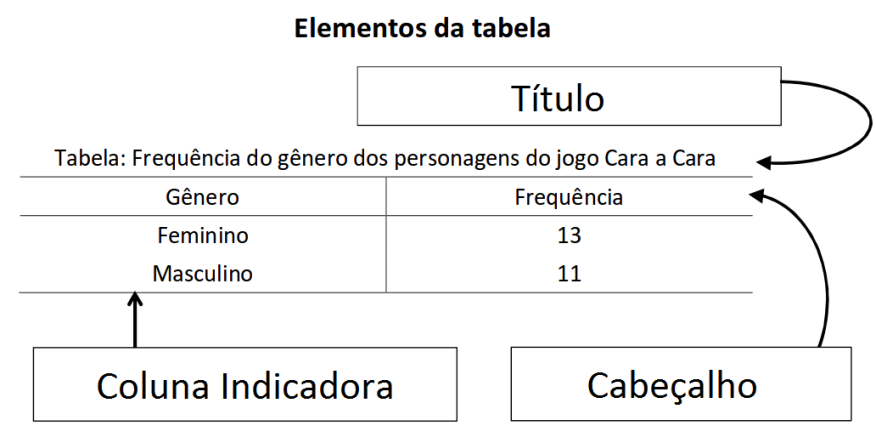

Figura 2. Exemplo de exercício realizado com tabela simples 
V Congresso Brasileiro de Informática na Educação (CBIE 2016)

Anais do XXII Workshop de Informática na Escola (WIE 2016)

A partir das tabelas, repetiram-se os questionamentos anteriores, os quais foram respondidos de forma bem mais rápida e sem divergências. Embora, tenha sido claramente percebida a facilidade de responder os questionamentos a partir das tabelas, foi reforçada a diferença entre se trabalhar com os dados organizados e a ficha de coleta.

Materiais: foram utilizadas fichas de coleta, preenchidas na aula anterior, e folhas de exercícios com tabelas simples incompletas.

\subsection{Aula 4 - Representação de dados por tabelas duplas e análise dos dados}

Objetivos: construir tabelas duplas, identificar a necessidade de outras formas de representação de dados, construir tabelas compostas e analisar dados.

Metodologia: a aula começou com a entrega das fichas de coleta preenchidas. Após a entrega, relembrou-se rapidamente o assunto visto na última aula, que foram as tabelas simples, bem como os elementos das tabelas. De maneira similar ao encontro anterior, motivou-se a construção de tabelas duplas por meio de questionamentos sobre a amostra. Por exemplo, quantos personagens do sexo feminino usam óculos? Há mais personagens do sexo masculino ou do sexo feminino que não usam óculos? A partir de então, foram apresentadas as tabelas duplas, utilizadas quando duas características devem ser analisadas conjuntamente, e foram descritos os principais elementos destas tabelas. Novamente, foi construída uma tabela em conjunto com os alunos e novos exercícios de construção de tabelas e perguntas sobre os dados representados foram propostos aos alunos (a Tabela 2 é um exemplo de tabela dupla usada nas aulas). Por se tratar da última aula de tabelas, a conclusão desta atividade foi refrisar quais são os itens obrigatórios presentes nas tabelas, qual a diferença entre tabela simples e tabela dupla.

Tabela 2. Exemplo de tabela dupla utilizada em aula: "Tabela de frequência dos personagens que usam óculos separados por gênero"

\begin{tabular}{c|c|c|c}
\hline \multirow{2}{*}{ Gênero } & \multicolumn{2}{|c|}{ Usa Óculos } & \multirow{2}{*}{ Total } \\
\cline { 2 - 3 } & Sim & Não & \\
\hline Masculino & 3 & 8 & 11 \\
\hline Feminino & 3 & 10 & 13 \\
\hline Total & 6 & 18 & 24 \\
\hline
\end{tabular}

Materiais: foram utilizados fichas de coleta, cartaz com os personagens do Cara a Cara e tabelas a serem preenchidas e questionamentos sobre os dados.

\subsection{Aula 5 - Representação de dados por gráficos e análise de dados}

Objetivos: apresentar representações alternativas para dados organizados em tabelas simples e duplas.

Metodologia: no início da aula, foi realizada uma revisão sobre tabelas simples e tabelas duplas, relembrando sempre a relevância destas formas de representação de informações quando se lida com uma grande quantidade de dados. Após, os alunos foram introduzidos à construção de gráficos de colunas. Os gráficos foram apresentados aos alunos como uma alternativa à representação de informações, que podem ser definidos a partir de tabelas simples ou duplas. Introduz-se o sistema cartesiano de coordenadas, composto por dois eixos, um vertical (y) e outro horizontal (x). No eixo horizontal são alocados os 
V Congresso Brasileiro de Informática na Educação (CBIE 2016)

Anais do XXII Workshop de Informática na Escola (WIE 2016)

valores da característica e no eixo vertical, as frequências. Cada valor da característica é representado por uma coluna cuja altura é delimitada pela sua frequência. As colunas devem possuir a mesma largura e a distância entre elas deve ser constante. Para construir gráficos a partir de tabelas duplas, escolhe-se uma das características, gênero, por exemplo, cujos valores (masculino e feminino) são alocados no eixo $x$ e agrupam os valores da outra característica, usar óculos por exemplo, que são representados por colunas justapostas de cores diferentes. Também são apresentadas as funções do título e legenda nos gráficos. A partir de então, gráficos são construídos para as tabelas definidas nos encontros anteriores. O Gráfico 1, construído a partir da Tabela 2, é um exemplo de gráfico utilizado nas aulas.

Materiais: folhas de exercícios, que incluem construções de tabelas, gráficos e questionamentos sobre os dados representados.

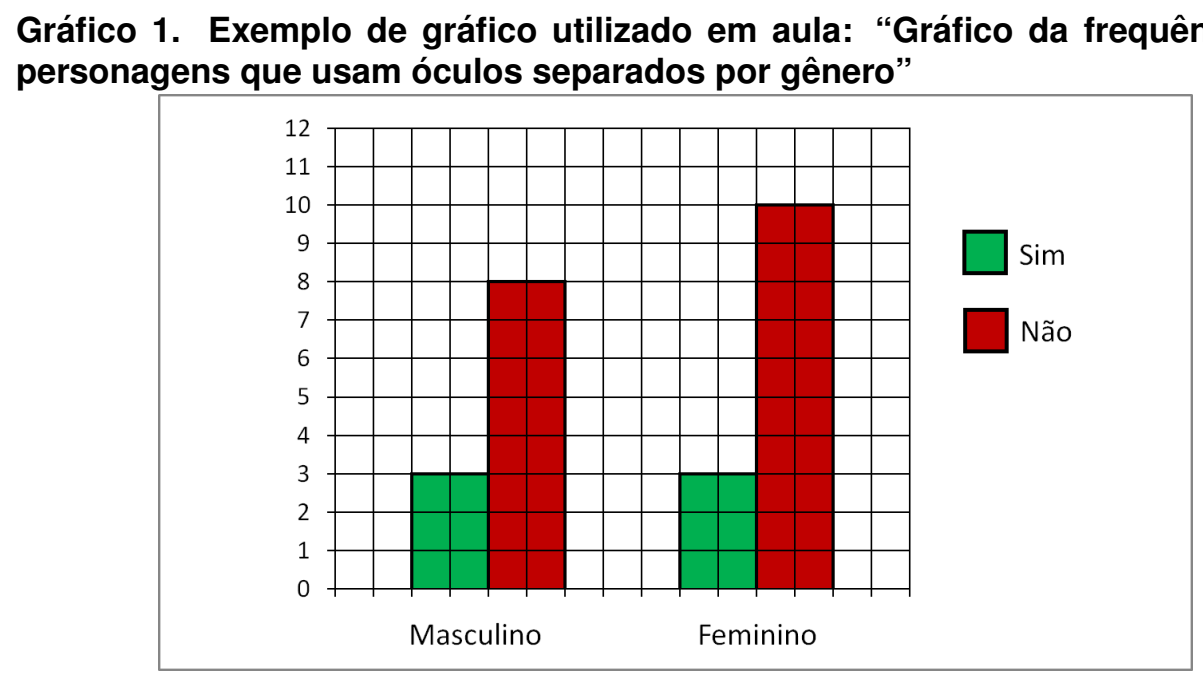

\subsection{Aula 6 - Jogando o Cara a Cara}

Objetivos: evidenciar características relevantes de uma amostra em um contexto específico, particularmente na execução do jogo Cara a Cara, e utilizar tabelas e gráficos para delinear a melhor estratégia a ser adotada para vencer o jogo.

Metodologia: a turma foi organizada em duplas e as regras foram estabelecidas. Cada jogador recebe um tabuleiro, uma carta com um personagem a ser descoberto pelo adversário e um baralho de cartas com todos os personagens. Cada jogador encaixa as cartas do baralho no seu tabuleiro na posição vertical. O objetivo do jogo é adivinhar o personagem recebido pelo adversário. A cada rodada um jogador tem direito a fazer uma pergunta de resposta sim/não para tentar adivinhar o personagem do adversário (por exemplo, se o personagem é do sexo masculino). Ao receber a resposta, o jogador pode eliminar alguns personagens do seu conjunto de candidatos, os quais devem ser baixados para a posição horizontal. Ganha o jogo aquele que adivinhar o personagem do adversário com menos perguntas. Inicialmente, os alunos jogaram livremente. Em um segundo momento foi solicitado que eles usassem as tabelas e gráficos, construídos nas aulas anteriores, para definir a melhor estratégia possível para ganhar o jogo, ou seja, fazer a pergunta que eliminasse o maior número de personagens a cada rodada. Por fim, por meio da seleção de personagens aleatórios e com base nas representações e dados já 
V Congresso Brasileiro de Informática na Educação (CBIE 2016)

Anais do XXII Workshop de Informática na Escola (WIE 2016)

realizadas, foram definidas e analisadas estratégias que considerassem o menor número possível de perguntas.

Materiais: tabuleiros confeccionados em papelão e cartões de personagens coloridos impressos. Folhas de exercícios resolvidas em aulas anteriores com a tabulação e representação gráfica das frequências das características envolvidas.

\subsection{Aula 7 - Avaliação}

Objetivos: avaliar o conhecimento adquirido por parte dos alunos.

Metodologia: as folhas de avaliação foram distribuídas e, então, foi feita a leitura das questões em voz alta. Foi recomendado aos alunos que não se preocupassem em responder as perguntas que não soubessem ou não tivessem certeza. A avaliação compreendeu 5 questões, valendo ao todo 10 pontos, que são descritas a seguir: as duas primeiras questões, ilustradas na Figura 3, tratavam dos conceitos estatísticos básicos; a terceira questão apresentava uma tabela de frequência simples e continha dois itens que perguntavam sobre os dados da tabela e um terceiro item que solicitava classificar a tabela como simples ou dupla; a questão 4 ilustrava uma ficha de coleta preenchida e era solicitado que fosse construída uma tabela de frequência simples para uma determinada característica e o correspondente gráfico de colunas, ainda, na mesma questão quatro itens questionavam sobre os dados da ficha de coleta e das representações construídas; e a questão 5 apresentava uma ficha de coleta e solicitava a construção de uma tabela dupla e do correspondente gráfico de colunas.

Materiais: folhas de avaliação.

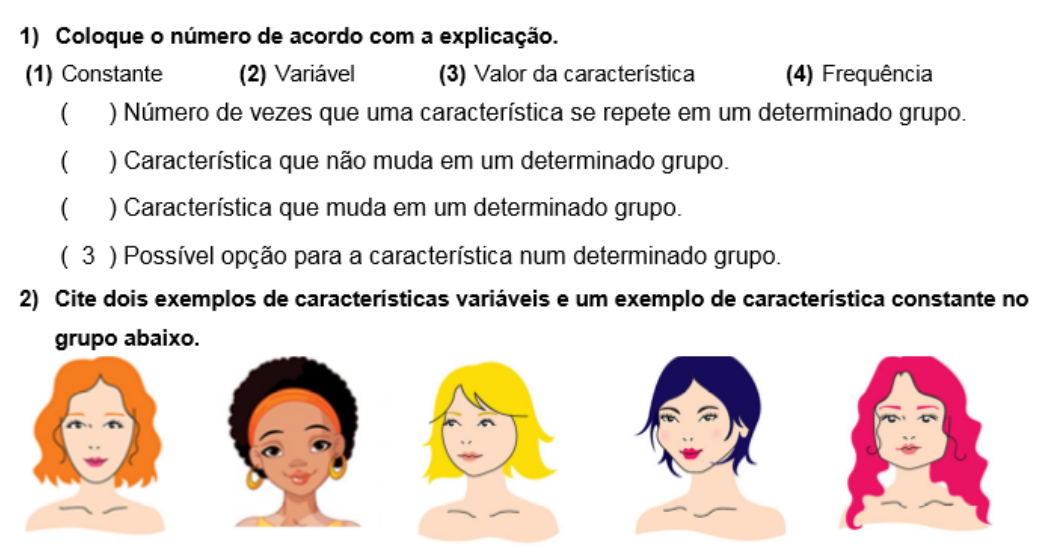

Figura 3. Parte da avaliação da atividade Cara a Cara

\section{Resultados e Discussão}

As duas escolas que participaram do projeto têm perfis diferentes. FV é uma escola de periferia, que se caracteriza por atender alunos, predominantemente, oriundos de famílias com escolaridade e renda baixas. A escola P, por sua vez, se localiza no centro da cidade e é composta por alunos com situação socioeconômica mais diversificada.

Por meio de um questionário, os alunos foram caracterizados quanto ao acesso a equipamentos eletrônicos: $76 \%$ do total de alunos responderam que utilizam computadores ou smartphones todos os dias; e o percentual de alunos com internet em casa é de $82 \%$ nas turmas FV e $94 \%$ na turma $\mathrm{P}$. 
V Congresso Brasileiro de Informática na Educação (CBIE 2016)

Anais do XXII Workshop de Informática na Escola (WIE 2016)

Quanto ao uso de redes sociais e jogos eletrônicos, verificou-se que em torno de 90\% dos alunos da turma P e 83\% dos alunos das turmas FV têm perfil no Facebook; e, em todas as três turmas, mais de $90 \%$ dos alunos responderam que apreciam jogos de computador, e em torno de $30 \%$ costumam jogar todos os dias.

Os alunos gostaram bastante de participar dos jogos. Observou-se, no jogo da aula 1 , que alguns faziam perguntas similares às já feitas por colegas, sem se preocupar com a diferenciação dos personagens. Sempre que observado, chamava-se a atenção para focar na melhor estratégia para ganhar o jogo. Na etapa de levantamento de características, os grupos geralmente listaram características variáveis. Houve sugestões de características que não eram possíveis de serem observadas na amostra. Já a coleta de dados foi realizada de forma correta e com facilidade por praticamente todos os alunos. Na representação e análise de dados, em geral, os alunos demonstraram mais facilidade de construir tabelas do que gráficos. Algumas vezes, mesmo com o gráfico na frente, buscavam a tabela para analisar os dados. A descrição do desempenho dos alunos na avaliação da atividade e os resultados do teste de comparação de médias das turmas são apresentados na Tabela 3.

Tabela 3. Descrição do desempenho geral dos alunos, por turma, na avaliação
da atividade
\begin{tabular}{|l|lll|lllll} 
Turma & $\mathrm{n}$ & Média & DP & Mínimo & $Q_{1}$ & Md & $Q_{3}$ & Máximo \\
\hline $\mathrm{P}$ & 18 & 7,2 a & 1,46 & 4,2 & 6,3 & 7,5 & 8,2 & 9,2 \\
FV T1 & 26 & 7,1 a & 1,80 & 2,7 & 6,3 & 7,7 & 8,2 & 9,3 \\
FV T2 & 22 & 6,7 a & 1,90 & 2,6 & 5,9 & 7,0 & 8,0 & 9,6 \\
\hline Geral & 66 & 7,0 & 1,74 & 2,6 & 6,0 & 7,5 & 8,2 & 9,6 \\
\hline
\end{tabular}
Nota: $\mathrm{n}=$ número de alunos; DP = desvio padrão; $Q_{1}=$ primeiro quartil; Md $=$ mediana; $Q_{3}=$ terceiro quartil.
Médias seguidas de mesma letra não diferem entre si pelo teste DMS de Fisher $(\alpha=0,05)$.

A pontuação dos 66 alunos avaliados variou entre de 2, 6 a 9, 6, com média 7, 0 e coeficiente de variação $24,9 \%$, o que evidenciou a heterogeneidade do grupo, mas apresentou um desempenho geral satisfatório. $\mathrm{O}$ valor do primeiro quartil $\left(Q_{1}\right)$ revela que $75 \%$ dos alunos alcançaram nota maior ou igual a 6,0. Quando a avaliação foi efetuada por turma, observou-se que os três grupos possuíam médias muito próximas. Os coeficientes de variação (20,2\%, para P, 25, 4\%, para FV T1 e 28, $4 \%$, para FV T2) evidenciaram que a turma $\mathrm{P}$ foi um pouco mais homogênea que as turmas FV (T1 e T2) em relação às notas. O teste de comparação de médias confirmou que não houve diferença significativa entre as três turmas. Isso sugere que o perfil da escola não afetou o desempenho dos alunos na avaliação. Contudo, o comportamento dos alunos em sala de aula variou entre as escolas. Durante as aulas, os alunos da escola FV se mostraram mais interessados e motivados para os jogos e as tarefas propostos. Isso talvez possa ser explicado pelo fato de que as aulas foram ministradas por professores (alunos bolsistas) diferentes nas três turmas. A interação entre o professor e a turma é um aspecto que não pode ser ignorado. É possível que um professor tenha tido maior habilidade que outro para motivar as crianças. Embora tenha sido feito um treinamento prévio com os ministrantes, diferentes estratégias didático-pedagógicas devem ser analisadas e estabelecidas de acordo com o perfil dos estudantes. A relação professor-aluno e a utilização de exemplos próximos ao dia-a-dia das crianças são fatores que parecem impactar diretamente na motivação dos alunos. 
V Congresso Brasileiro de Informática na Educação (CBIE 2016)

Anais do XXII Workshop de Informática na Escola (WIE 2016)

\section{Conclusão}

Este artigo contribui com uma proposta e relato de aplicação de uma atividade que busca introduzir conceitos básicos de tratamento de informação para alunos do quinto ano do Ensino Fundamental. É possível afirmar que a atividade se mostrou satisfatória na introdução dos conceitos de coleta, análise e representação de dados.

O trabalho foi desenvolvido para ser adaptado à realidade da maioria das escolas públicas, a fim de tornar a atividade de fácil aplicação, não sendo necessário o uso de computadores para sua execução e fazendo uso de exercícios lúdicos, inspirados em um jogo de tabuleiro já conhecido. Os materiais utilizados nas tarefas propostas foram pensados de forma a manter o baixo custo de obtenção e maior durabilidade.

Acredita-se que a disseminação do PC no ensino básico pode trazer importantes contribuições na formação de alunos com respeito à resolução de problemas. Organização, representação e análise de dados, identificação, análise e implementação de soluções eficientes e eficazes, entre outras, são habilidades úteis tanto para o dia-adia quanto para a solução de problemas em diversas áreas, que podem ser promovidas desde a infância, e de maneira interdisciplinar, por meio do PC. Como trabalhos futuros, espera-se desenvolver novas atividades que promovam o PC para escolas da rede pública, abrangendo também turmas de diferentes faixas etárias.

\section{Referências}

Andrade, D. et al. (2013). Proposta de atividades para o desenvolvimento do pensamento computacional no ensino fundamental. In Anais do WIE 2013, pages 169-178.

Arantes, F. L. et al. (2014). Nos rumos da autonomia tecnológica-desafios e lições aprendidas para a formação de jovens. In Anais do WIE 2014, pages 308-317.

Bell, T., Fellows, M. R., and Witten, I. (2015). Computer science unplugged. http: / / csunplugged.org/books. Acessado em Agosto de 2016.

Costa, T., Batista, A., Maia, M., Almeida, L., and Farias, A. (2012). Trabalhando fundamentos de computação no nível fundamental: experiência de licenciandos em computação da Universidade Federal da Paraíba. In Anais do WEI 2012, pages 1-4.

Estrela (1986). Brinquedos - cara a cara. http://www.estrela.com.br/ brinquedo/cara-a-cara/. Acessado em Agosto de 2016.

Machado, E. et al. (2010). Uma experiência em escolas de ensino médio e fundamental para a descoberta de jovens talentos em computação. In WEI 2010, pages 799-807.

MEC (1997). Parâmetros curriculares nacionais. http: / / portal . mec.gov.br/ seb/arquivos/pdf/livro01.pdf. Acessado em Agosto de 2016.

Scaico, P. D. et al. (2012). Relato da utilização de uma metodologia de trabalho para o ensino de ciência da computação no ensino médio. In Anais do WIE 2012, pages 1-10.

Thinking, C., Board, C., Sciences, D., and Council, N. (2010). Report of a Workshop on the Scope and Nature of Computational Thinking. National Academies Press.

Vieira, A., Passos, O., and Barreto, R. (2013). Um relato de experiência do uso da técnica computação desplugada. Anais do WEI 2013, pages 670-679.

Wing, J. M. (2006). Computational thinking. Communications of the ACM, 49(3):33-35. 